\title{
Inside the Learning Assemblage: Japanese Parents' Views of Children's Learning and Future Possibilities
}

\author{
Karen Guo ${ }^{1, *} \&$ Kiyomi Kuramochi ${ }^{2}$ \\ ${ }^{1}$ Deakin University, Australia \\ ${ }^{2}$ Tokyo Gakugei University, Japan \\ *Corresponding author: Deakin University, Australia. E-mail: kareng.guo@ deakin.edu.au
}

Received: May 12, 2019 Accepted: May 29, 2019 Published: June 7, 2019

doi:10.5296/ije.v11i2.14771 URL: https://doi.org/10.5296/ije.v11i2.14771

\begin{abstract}
In Japan, as in many other countries, young children's learning is subject to two major experiences: experience at home and experience in preschool. These experiences constitute the basis on which to formulate understandings about children's future possibilities. The aim of this study is twofold: to navigate Japanese preschool children's learning experiences and future possibilities in their families and preschools, as perceived by Japanese parents; and to discuss how learning is imbued in various distinct and interrelated elements of the home and preschool contexts. The study analyses children's learning through questionnaires of preschool parents in Tokyo and the observations of parent-child and parent-teacher interactions in the preschools. Following from Deleuze and Guattari's assemblage theory, children's learning is positioned within a dynamic assemblage of stable, fluid and transformative forces that leads to particular experiences and becomings. Placing parents' views at the centre of analysis of their children's learning, the study shows how they conceptualized children's experiences and their becomings as-and-in children's learning assemblages.
\end{abstract}

Keywords: Japanese Parents; Children; Learning; Preschool; Assemblage Theory 


\section{Introduction}

This project, to investigate the learning of Japanese young children from their parents' perspectives and experiences, is taken from a larger study on early childhood education in Japanese preschools. By means of semi-structured questions and observations of parent-child and parent-teacher interactions we purposefully included 130 Japanese parents in the study. Drawing on the information from the parents, our interest was to describe children's learning (kaihatsu) in their families and the preschools to explore stable, fluid and transformative forces that were perceived by the parents as exerting influences on children's experiences.

Past studies have provided abundant examples of children's learning in Japan, illustrating, for examples, play, socialization, care and responsibilities, bringing to light both the historical and contemporary discourses on the topic, for example the influence of Japanese religious belief in the divine nature of children (Izumi-Taylor \& Rogers, 2016), Frobel's self-activity, child-centred education from America and Europe, and the idea of creativity from Reggio Emilie (Burke, 2008). In the context of early childhood years, learning refers to kaihatsu and it consists of 'play in natural environments', 'physicality', 'experiencing social complexity' (Tobin, Hsueh, \& Karasawa, 2008, p.129; p.156), 'an emotion-centred emphasis' (Nanakida, 2015, p.29), sympathetic relationships (Izumi-Taylor, 2013), everyday life experiences (Lee, Takenaka \& Kanasue, 2015), 'socialization of children based on cultural values' (Izumi-Taylor \& Rogers, 2016, p.212), self-regulation, self-reliance, doing tasks (Hegde, Sugita, Crane-Mitchell, \& Averett, 2014), becoming 'the strong individual' (Aspinall, 2016, p.136), and developing into 'fully functioning members of their own country' (Burke, 2008, p.152). Overall, in young children's lives in Japan, where free play and 'a good child identity' (Burke, 2008, p.150) are often given centre stage, the discourse of whole-child is a prevalent theme in children's learning (Hoffman, 2000; Yamamoto, 2016).

'Uchi'/ 'inside' and 'soto'/ 'outside' are two contextual terms that form the basis of socialization in Japanese society, thereby of children's learning (Burke, 2008). Appropriate behaviours are understood differently in the two contexts. Uchi serves diverse family cultures with distinct needs, while communities are situated in soto and are connected to the social culture. According to Hellman (2016, p.1694) while individual desires and selfishness may be acceptable in a private space, learning to 'hito ni meiwaku o kakenai' (not to cause trouble for others), it is a soto form of behaviours that functions through social practices. Burke (2008) also used the typology of uchi and soto to describe Japanese children's learning:

In contrast to the relative freedom of the $u c h i$ environment, when interacting in the soto world, individuals are expected to show enryo, which translates roughly as restraint or holding back. (p. 140)

Many discussions of Japanese parenting discuss what Yamomoto (2016) calls 'a good wife, wise mother'... with the very common notion that a woman commits to the role of mother or caregiver of family members (p. 84). Scholars have viewed the learning of Japanese children inside their families as constructing proper relationships with their mothers, through which building 'aspects of character seen as uniquely Japanese' (Burke, 2008, p. 139), namely knowing 'when, how, and on whom to be dependent or not dependent' (Hara \& Mingawa, 
1996, p. 11). Underpinned by the uchi-soto concept that is predicated upon the dualist logic of Japanese family and society, the paradigm practice of Japanese parents develops particular forms of knowledge for their children in terms of the difference between uchi and soto and how to adjust their behaviours accordingly.

The different experience between the uchi and soto worlds of young children has mattered a lot to Japanese. However, because of a significant increase in women's employment, a predominant economic decline, and an appalling drop in birth rates, 'what it means to good wife and wise mother continues to fall' (Burke, 2014, p. 61). 'Changes in family and family values have an effect on the sound growth of children [in Japan]' (Burke, 2014, p. 62) and as a result, the society has seen 'a decline in the quality of parenting over the past generation' (Tobin et al., 2008, p. 153). Even so, there is also evidence that Japanese children are well supported in their families (OECD, 2011). Evidence of Japanese parents' responsibility is also apparent in the study by Yamomoto, Holloway and Suzuki (2016), who found that Japanese parents, particularly mothers showed a clear sense of responsibility for their children.

It is in the context of such debates concerning Japanese children's learning within their families that we designed the current study. The purpose of this study is to report on the perspectives of Japanese preschool parents on children's learning. Since there is a legitimate need for understanding children's family experiences in Japan, and since, to our knowledge, no systematic investigation has been conducted on parents' views of children's learning in their uchi and soto worlds, a study of this nature certainly seems warranted. It is expected that the study not only contributes to an understanding of Japanese parents' perspectives and experiences with their children, but also to the construction and constitution of the whole-child ideology of Japanese young children.

\section{The Learning Assemblage}

The study discussed here is informed by Gilles Deleuze and Felix Guattari's (1987) assemblage theory and the associated concepts that position learning within a dynamic process of assemblage of stable, fluid and transformative forces that create particular experiences and future possibilities. According to Potts (2004), Deleuze and Guattari talked about assemblage as a process of forming 'a kind of chaotic network of habitual and non-habitual connections' (p. 19).

The making of an assemblage is interwoven with the generation of a territory. The importance of the word territory comes in the implication that 'assemblages are fundamentally territorial' (Kamalipour \& Peimani, 2015, p. 403). In addition, because of the changes, movements and deconstructions within each assemblage, territorial assemblage involves not only the action of territorialisation (stability) but also the forces of reterritorization (fluidity) and deterritorization (transformation) (Duff, 2016).

Another common term used to analyse assemblage is the concept of becoming, an evolving process or 'becomings evolve' (Deleuze, 1995, p. 45). As an essential point in their 
conceptualization, becoming takes a prominent part in Deleuze and Guattari's flows-connections-becomings model of assemblage (Duff, 2016). According to Semetsky (2010), by definition, assemblage is just a process of 'coming into being, (be-coming)' (p. 480) and in Bear's interpretation (2013), assemblage shows the evolvement of 'continuing trajectories and future possibilities or becomings' (p. 24).

Thus, territorial assemblage in its broad definition refers to a continuing trajectory, future possibilities or becomings. If a territory is taken to be an aggregate of various relations and movements, then becoming gives the direction to these movements. In this sense, the act of representing assemblage as a process of territorizing, reterritorizing or deterritorizing is possible through an understanding of becoming as an important contributor to the movements and flows. Colebrook (2002) noted that 'it is from this flux of becomings that we perceive or organize beings' (p. 145).

The process of becoming and the flux and movements inherent in a territory of assemblages take place through what Deleuze and Guattari (1987) refer to as a triad of lines: the molar line, the molecular line and lines of flights. These key elements of Deleuze and Guattari's ontology of becoming constitute the interactions between assemblage segments.

By illustration, we see the triad of lines as 'compositional, implying relation and connection...they propose an image of thought that is consistent with D \& G's ontology of a continuous movement of rest and becoming' (Windsor, 2015, p. 157-8). For Deleuze and Guattari, a territorial movement, whether it is the flows, connections and becomings, depends on the stimulation of 'qualitative emergence of the new' (1987, p. 168), and for this reason, the three lines as features of change and movement that lead to becomings suggest a complex and multi-faceted relational articulation. In terms of their function and operation, Deleuze and Guattari (1987, p. 205) contemplate that 'there is the molar line that forms a binary, arborescent system of segments, the molecular line that is more fluid although still segmentary, and the line of flight that ruptures the other two lines'.

The three lines draw attention to the fact that the process of assemblage takes place in a context of ongoing creation of the lines. Among these lines, the line of flight is considered as the one that 'evokes the spirit of desire lines as breaking away from prescribed pathways. Where molecular lines may loosen molar segmentarties, lines of flight are a decisive escape' (Windsor, 2015, p. 164), thus deterritorizing beings and developing becomings.

The current research aimed to explore Japanese parents' views and experiences of children's learning. Deleuze and Guattari's assemblage theory framed understandings about the assemblage of ideas, practices and relationships into a trajectory of becomings. In the course of our efforts to understand Japanese children's experiences on such things as their present and future lives, children's learning was understood as being constituted by a variety of stable, fluid and transformative forces in both the public and private spheres. In this paper, we focus in particular on the usefulness of the lens of assemblage to analyse how children's learning is expressed by their parents as multi-faceted territorial elements in their families and at the preschool that involves the connection of children to their future possibilities or becomings. 


\section{The study}

This was a qualitative study of Japanese parents' perspectives of preschool children's learning, using Deleuze and Guattari's assemblage theory to explore the two main contexts (home and preschool) in children's lives and how the various elements within these contexts stabilized and influenced children's experiences as well as created transformations in their learning. A basic tenet of the assemblage theory is that learning is a process of territorizing, reterritorizing and deterritorizing assemblages. Therefore, we carefully attended to the parents' perspectives and experiences, seeking to identify ideas that indicated stable, fluid and transformative elements in children's experiences, as well as how they formed children's future possibilities.

The two researchers were both university academics with one being a native Japanese educational professor. Our research paradigm was more concerned with description than measurement and used qualitative methods to develop a depiction of Japanese parents' perspectives of children's learning experiences. A sample of 130 parents from two preschools in Tokyo was selected for inclusion in the study and they consisted of all the families in the preschools.

The study included one university-based preschool and one public preschool. They were both located in middle class residential areas and served children aged from four to six in two different classes: four to five year olds and five to six year olds. Children and parents came from the neighbourhood families. The choice of these two preschools was made based on the consideration of their closeness to the Japanese researcher's work place. Economically and geographically, they were similar.

The parents' observations took place on three occasions in each preschool where we wrote down, photographed and video recorded parents' interactions with their children and their children's teachers when they came to pick up children. We have also observed them during a social event in each preschool with one as parent-teacher meeting and the other as a preschool concert. All the 130 families were under observation during the pick-up time and 48 parents were observed in the social events.

Within the questionnaires, the parents were asked about their beliefs in children's learning in their families and the preschools, children's learning experiences and parenting practices. Specifically, the parents were requested to write about their goals and concerns in relation to children's learning. All questions had been piloted with some preschool teachers to confirm that they were suitable for the parents.

A response rate of $90 \%$ was achieved from the parents' questionnaires. A total of 113 parents' replies were reviewed for the reason of their clarity and details. Among the 113 parents, 53 were recruited from the public preschool and they were all fulltime mothers. The other 60 parents came from the university-based preschool. Among them, there were five fathers. Out of the 108 mothers, 14 were working professionals. The questionnaires were presented in Japanese and translated to English by a professional Japanese-English translator.

Data were analysed by both researchers. The observational notes, photos and videos were 
reviewed many times with attention paid to how parents interacted with their children and their children's teachers. Salient excerpts were further analysed for themes in relation to the research topic. The original questionnaire schedule guided the analysis of the parents' questionnaires but the researchers also identified recurring points and ways referring to them. Relevant replies were grouped thematically for further analysis. In addition, the replies were analysed concerning the relevance to children's learning in the two settings, and how the two related, as well as parents' ideas on the stable, fluid and transforming factors. At each stage, the two researchers discussed emergent concepts, theoretical interpretations and decisions about data organization.

\section{Findings}

Participants in the study provided a range of perspectives and demonstrated certain behaviours in relation to the research topic. The way they expressed children's learning showed us not only the parents' views on children but also their understanding of relevant influences in children's lives.

\subsection{Learning within the Families}

Parents described their beliefs, practices and issues in relation to children's learning in their families. Among them, some were stable segments (molar), some were fluid (molecular) and some were transformative (line of flight).

\subsubsection{Stable Forces: Becoming Part of the Family}

Family influence on children's learning was mentioned in all the questionnaire replies. Participants from both preschools talked about how particular families raised particular children. Family influence, for the parents, included parents' education (46/113), parents' modelling (99/113), family behaviours (27/113), parents' attitudes to life (41/113), and family structure, namely the number of children who could play and grow together (77/113). Types of families and the family backgrounds were seen as foundational to what created a child and a learner.

When discussing their families, some parents (43/113) made direct references to the relationship between marital partners. They talked about how this relationship influenced children's learning. One mother stated that "how my husband and I treat each other is important in my child's learning'. It is not only the mother-father relationship that influenced children's learning but also the relationship between the parents and children, in particular, the relationship between a mother and a child. 87 parents ( 86 mothers) discussed how, in their families, the mother played the main role in helping with a child's learning: 'my wife is the key carer in my son's growth and learning. They are close and spend lots of time together' (one father). This idea allows us to see that 'the good wife, wise mother' tradition is still evident in many families of the present study.

Children's daily routines, namely what they did each day in the families also featured significantly in the discussions of the children's learning (72/113). For most parents, their 
children had fixed routines on week days. Among all the routines, helping with housework such as preparing cooking appeared to be central in many children's routines and through this, the parents believed that 'children learn to be part of the family'.

Through the parents' descriptions, it is evident that being part of the family is a central becoming in children's learning. Family structures, daily routines, and family relationships appeared to provide children with stable and structured experiences through which they became members of the family.

\subsubsection{Fluid Forces: Becoming Respected Individuals}

Deleuze and Guattari (1987) discussed the molecular line as a fluid line. In this study, molecular elements were viewed as experiences or influences which were not as fixed, stable or absolute but they were still important aspects of children's experiences. In their replies, parents made reference to children's siblings (38/113), family conversations (59/113), children's behaviours in the families (96/113), family rules (21/113) (e.g. TV time), and parents', mainly mothers' childrearing styles (84/113). The reason why these elements were categorized as molecular segments was because either parents' expressions were not certain when making these points (using for example, may, should) or parents indicated clearly that these elements were changeable. For example, 'I do not have a particular style with my child. I change according to her mood'; 'we have some basic rules with our children but depending on the situation, rules are flexible'. We have also observed a conversation between a mother and a child that illustrates a process of negotiation:

Mother: can you help me make the meal today?

Child: as soon as we are home?

Mother: yes?

Child: do I have to do it the first thing home?

Mother: yes, but why?

Child: Chotan just lent me a book. I want to read it.

Mother: ok, you can read it first. That should be fine.

In their expressions, the parents commented on how in their families, they negotiated with children about some aspects of children's lives such as 'where to go', or 'how long we watch TV today'. Many mothers (71/113) talked to their husbands about their children and they tried to make decisions together. In this way, the mothers offered themselves and their children a permitted break from a fixed life experience.

The parents also discussed what children should be learning within the families. Even so, for some of them (42/113), this was dependent on children's personalities and preferences, and also the ways in which parents talked to children. This is particularly so for some working mothers: 'I am a working mother. I do not always teach him. What he learns depends a lot on what he wants'. 
One particular function of molecular lines is to reconstruct the molar lines (Deleuze \& Guattari, 1987). Through ongoing experiences with their children, parents changed some aspects of apparently established territorial segments, for example, their relationships with children: 'I always learn to be a better mum so my relationships with my children are getting better and better'. In further examples, some parents (46/113) spoke about how through listening to their children, the parents understand the children better, so 'I adjust my communications with her'.

As seen in the parents' data in relation to the molecular line, some important features of children's learning stemmed from the parent's uncertainties about children's learning, parents' flexible attitudes to children, parents' open communications with children and parents' desire for parenting improvement. These fluid segments were pervasive constituents in children's learning and highlighted how children's experience could be situational, contingent on their, their parents, and the families' evolving needs for connection and improvement. These molecular segments, or perhaps even the need for them, portray the parents' desires and their efforts to become better parents. It seems, ultimately the aim is to shift what have been constraining arrangements in children's learning to better enable children to become respected individuals.

\subsubsection{Line of Flight: Becoming Playful, Interested and Real Life Explorers}

Deleuze and Guattari (1987) define the line of flight as a breakaway from stable pathways for another world of possibilities. In the current study, three significant themes were evident in the parents' data that linked children's learning to breakaways. First, almost all parents believed (104/113) that moments of real learning arose when children were playing and when they were making choices, solving problems, experiencing difficulties and exercising their autonomy. 'Everything could happen when he plays. He can learn anything that I cannot imagine'. The parents understood that in play, the processes and experiences were couched primarily in terms of children's own ideas which could be beyond parents' plans and imaginations: 'play provides children with an open-ended learning experience and process, so they could learn anything possible'. In addition, some parents indicated that they also played with children and from these experiences learned about their children. These experiences provided parents with ideas to ponder about their attitudes to life and approaches with children.

Second, the parents stated that real life experiences could develop a mere novice into competent and skilled actor, playing a role as 'unspoken instructions' which the parents highly valued. Again, real life experiences were pointed out as another strong theme in the parents' expressions (105/113). As one parent remarked, 'nothing is more valuable than real life experience because in real life, they learn anything they need, anything they do not know, anything we don't know'. For the parents, real life experiences included not only household chores such as preparing a meal but uncommon problems, for example, 'being locked out', or 'losing the dog'. Overall, the parents emphasized the importance of real life experience as an avenue which actualized both expected and unexpected learning experiences by making visible both practical and impractical situations for children while constructing such 
situations as natural and therefore lending itself perfectly to children's curiosity and their development into problem solvers.

Third, the idea of children's interest in learning was mentioned so frequently (109/113) that it was seen as another prevalent theme in the parents' expressions. When talking about children's interest, the parents tied it to the notions of 'children's own way', 'children lead their learning', 'any kind of learning', 'diverse and unpredictable results', 'passion', 'engagement' and 'persistence'. Children's interest seemed to share similar characteristics with play and real life experiences, creating unplanned and evolutionary learning processes and outcomes.

Together, play, real life experiences and children's self-interests created the line of flight in which learning emerged as something that opened up to not-yet-known. For Deleuze and Guattari (1987) there was a space in which the line of flight coupled with other lines to produce unintentional expectations. As the three prevalent themes in the parents' expressions, children's free play, real life experiences and children's interests were desirable approaches to learning and because of this, the parents all expected them to be integral parts of children's development. In this sense, these lines of flight had both the dimensions of territorization and deterrtorization, being able to influence stable and fluid pathways, such as parents' attitudes to life, and child-parent relationships, thereby setting up new molecular and molar segments. In this sense, children themselves and what they did and chose to do led to the movement of deterritorization in their learning.

\subsection{Learning at the Preschool}

The analysis of the parents' questionnaires and observations identified a range of themes that appeared to be related to children's learning in the preschools. These themes were daily tasks, kindergarten rules, group life, classroom organization, play, children's peers, child-initiated activities, teachers' teaching, teachers' behaviours, teacher-child relationship, and teachers' attitudes.

\subsubsection{Stable Forces: Becoming Part of the Group}

In the parents' data (78/113), preschool rules and daily tasks were stable and structured experiences that children needed to do and follow. These rules included for example 'sitting at the desk', 'listening to the person who is talking', or 'cooperating with others'. Parents understood rules and tasks as fixed daily schedules or responsibilities and contributions that children must make, for example, 'doing what they are asked by teachers'. Some parents (38/113) understood that at the preschool, their children needed to properly put away, pack up and look after their own bags. This kind of learning structure was viewed as wonderful for the parents $(29 / 113)$ because 'children learn to be organized in the group'.

It was also apparent in the observations that the parents closely guided the children to follow the preschool tasks and rules. The parents were seen waiting with patience when children tidied up, or reminding children to walk in line and listen to the teachers during the preschool concert. The following excerpt shows this: 
A child is walking to his mother but he suddenly remembers: 'I forgot to put away my chair'. The mother says: 'go back and do it'. The child runs back to the class.

A key point by the parents was that joining in a preschool meant that a child started his or her group life (99/113). Preschool experiences were seen as related to organized events and to the learning with people in a social environment, or as tied to the routines and activities associated with living in a group setting. For the parents, group life was a remarkable feature of children's learning experiences so they believed that 'a preschool is a place that children learn about group life'. 'Group life is a definite experience in the preschool' and 'children should become part of the group'.

The importance of some aspects of the classroom organization, namely play space, indoor and outdoor areas, or pace of learning was another salient remark in parents' data (57/113). The paradigm of classroom organization was well received by parents (41/113) who believed that the values and attitudes they aimed to reinforce with their children as social beings were reflected in the classroom organizations: 'the preschool provides a good balance between play and learning'; 'I like it when the indoor and outdoor areas are spacious'; 'the learning activities seem to be very well arranged and very appropriate for my child's age and needs'.

Obviously, most parents agreed that part of children's learning in the preschools could be characterized by a core of ideas and practices such as rules, tasks, group life and classroom organization that was aimed at providing children with stable and well-arranged learning opportunities and developing children into members of the group.

\subsubsection{Fluid Forces: Becoming Autonomous and Communicative Social Players}

In describing their children's preschool learning, parents (84/113) also talked about play, child-initiated activities, children's peers and they viewed preschools not only as structured classrooms but also a flexible, open and relational place: 'at the school children play and do a lot what they want to do by themselves or with peers' and 'I understand preschool as a pretty free place where children play, learn and have lots of fun with friends'. We categorized these segments as the molecular line because the parents' conceptions of the open, flexible and relational nature of these segments coincided with the fluid and loose feature of the molecular line.

The fluid feature of molecular line was evident in parents' views of children's play that drew on children's individual interests, group needs and teachers' desires. For example, a parent commented: 'Through play, children develop a sense of self recognition, skills and basic habits and rules of living in the preschool group'. For some parents (39/113), play at the preschool was not merely a free experience, but an organized and purposeful activity: 'I hope that my child plays in many ways, for himself, with friends and in the activities arranged by his teachers'. As seen in this point, the parents gave different meanings to children's play. For them, unlike in the families where play was self-exploratory and free, at the preschool, play was organized and purposeful.

Parents talked about child-initiated experiences and children's own choices at the preschool (87/113). These included 'talking to teachers about his idea', 'negotiating with others what 
they can do together', 'making suggestions in the group', or 'expressing himself when listening to others'. As seen in these points, the parents did not mean that child-initiated experiences were purely created by the child. They should instead go side by side with teachers' directions and peers' support. One parent said clearly that 'I want my child to have a balanced experience between what he wants and what the group want him to do'. The reason why the parents did not want child-initiated experiences to be dominant in children's learning is because 'in the preschool, it is important that my child learns to accommodate other ideas' and 'it is no good that a child only follows his mind'.

Other children or children's friends is a term that has appeared in almost all parents' $(110 / 113)$ expressions. There was a very clear sense in which the parents related children's learning to children's friends when the parents recognized other children as a key contributor to their children's learning: 'playing with peers is important because children learn by mutual inspiration and stimulation'; 'I believe that children learn a lot when playing with peers of similar age'; 'although they fight sometimes, peers can progress together'. Even so, it was also recognized that 'I want my child to be able to make the judgement between good and bad friends because he may go wrong if mixed with wrong friends'. In talking about friends, the parents listed children who were 'bullying', 'speaking bad words', 'not polite', or 'breaking rules' as those their children should try to avoid and the 'kind', 'caring', 'helpful', 'happy' or 'empathetic' children were ideal peers for their children. The parents took the view that 'children's relationships with peers should be free but they also need to be monitored and supported by adults'. This indicates the parents' perception about the fluid nature of peers and peer experiences in children's learning.

\subsubsection{Line of Flight: Becoming Teacher-supported Learners}

There was recognition across all the parents' data (113/113) that children's teachers and their teaching were the most important element that determined and developed children's learning in the preschools. Parents believed that teaching was manifested in teachers' capacity to shape and change children's learning experiences, and therefore had a transformative potential in children's learning: 'if teachers can give children an environment where children feel accepted and secure, children can learn the best'; 'although it is important that he can make his own choices, at the end of the day, it is still the teachers he needs to follow'. Underpinning these data is the recognition that teachers are fundamentally the transformative factor in children's learning in the preschools.

The reason why parents attributed children's learning transformation to teachers was articulated through the ways in which teachers were described as 'the best guide', 'most important model that my child imitates', 'provider of the learning environment', 'decision markers' and 'professionals who know how to teach children'. Parents said very clearly: 'how teachers treat my child hugely influences how well he can learn'; 'teachers have the ability to see new interests from children so they are the best people to lead children to new learning opportunities'. As these points illustrate, teachers were viewed as being able to create new experiences for children.

Following from the parents' data, it could be said that teachers were the line of flight in 
children's learning experiences in their preschools. From the assemblage perspective, this view of teachers as the line of flight is because of the importance of respect in the Japanese culture, Japanese parents' emphasis on education and their trust on teachers' professionalism (Jones, 2017). It was very obvious in the parents' observations that they showed respect to teachers in ways that they actively listened and positively responded to teachers, they smiled when meeting teachers, and they waved goodbye to teachers and also reminded their children to do so. We observed the following conversation between a mother and her child:

Mother: I'm coming to help sew a cloth.

Child (smile): oh.

Mother: your teacher wants me to help. You should listen to her because she knows what is right.

The data in the study made apparent that to view teachers and their teaching as crucial forces in transforming children's' learning, the parents held many expectations for teachers and these expectations were once again indicators of the teachers' role as the line of flight in children's preschool beings: 'I want the teachers to help my child reach his potentials'. Viewed from this perspective, becoming teacher-supported learners was an important expectation that the teachers held for their children.

\section{Discussion}

The analysis of the findings indicates three concurrent and analytically interrelated territorial lines found in the parents' accounts of Japanese children's learning in their families and at the preschool and these lines give evidence not only about children's current experiences but also their future possibilities, thereby sketching children's learning trajectories.

First, family and preschool structures, such as parents' education and preschool routines, provided stable positions, or the molar line, which allowed children to construct their role in the two territories and in this sense, learning meant becoming part of the families and preschools. Second, family practices and preschool activities were highlighted as important in guiding children in ways that children reconstructed their learning through for example, negotiating with parents, or playing with peers. While these experiences were practical and flexible, they were predictable in a way that certain structures, such as family rules or teachers' teaching could confine their movements. These molecular segments were thus viewed as reconstruction elements in children's experience and learning meant becoming respected individuals and autonomous and communicative social players. Third, parent's accounts and experiences pointed out free play, everyday experiences and children's own interests in their families and children's teachers at the preschool as the segments in the two territories that were able to deconstruct children's learning and develop playful, interested and real-life explorers. Not only did these lines of flight transform children's learning, but they also reinforce or otherwise deterritoriate roles and functions of other territorial segments, creating the 'possibility and necessity of flattening all of the multiplicities' of the learning 
territories (Deleuze \& Guattari, 1987, p. 2).

As seen in the study, molar and molecular dimensions of children's learning are functions of the capacity of stable and fluid pathways to serve as social and cultural means, thereby developing 'fully functioning members of their own country" with 'aspects of character seen as unique Japanese' (Burke, 2008, p. 252). Family structures, family practices, preschool groups, routines, rules and relationships were all stable or pragmatic components of Japanese families or society. In making these points in relation to children's learning, parents indicated their close affiliations to their own culture and they expected their children to do the same.

Parents' perspectives of children's learning are not only forged on the basis of what children do to maintain their own cultural and family practices but also how they should move beyond. Viewing free play, everyday experience and children's interests as the line of flight that leads to a breakaway in children's learning in their families can be seen as a positive affirmation of the parents of the significant contribution of open and unstructured experiences to children's learning and also as parents' recognition of the unknown, unpredictable and child-led potentials that may emerge as an important part of the multiplicity of children's experiences.

It appears, then, that for the Japanese parents not only children's interests and their everyday experiences are implicated in children's move to breakaways. Children's teachers are a significant factor in this process. Many statements use the notion of teachers as the source of transformation in children's learning in the preschools. The emphasis on teachers is accompanied by their high respect to teachers during the arrival and social events. In this it is possible to see that there is a desire of the parents for developing children's learning through children's teachers (Jones, 2017). This is a concept that is gaining popularity in Japan as more mothers participate in the workforce (Tobin et al., 2008). There were talks about teachers' modelling, teachers' attitudes, teacher's teaching, and teachers' relationships with their children. Teachers were seen as constitutive of children's positive becoming as well as serving to make possible any process of learning rupture, in that teachers were perceived as being able to transform other elements, for example, children's play, a molecular segment, into a positive becoming through teachers' support and their teaching.

Although the parents identified a range of parenting actions and behaviours as important segments in children's learning territories, it is important to note the absence of parents themselves in their expressions. When giving high importance to teachers as the potential rupture that could create unforeseen possibilities in children's learning, the parents did not view themselves as a transformative segment. This is an interesting finding. Our interpretation is that parents' expectations of children's future are more associated with children's experiences in their soto world than in their uchi spheres (Yamamoto \& Holloway, 2010).

Through the assemblage model to identify line of thoughts, we realized that we needed to deterritorize children's learning between the territories and also reterritorialize new becomings in an interrelated context so as to understand children's whole child trajectory. In our reading of the children's territories as an assemblage, we traced how their learning was assembled in the families and preschools. As shown in the current study, the mapping of the 
constructive, reconstructive and deconstructive forces in children's learning, or the three territorial lines had created the potential for early childhood education in Japan to seek out stabilities (constructive segments/molar lines), practicalities (reconstructive segments/ molecular lines) and uncertainties (deconstructive segments/line of flight) in children's learning contexts and thus created an important space for the desirable possibilities of children's continuous learning.

What is the important space for the desirable possibilities of children's learning as a whole child? We learned in this study is that there is no natural being in children's learning that can be easily revealed; children's learning is a product of structured, evolving and multifaceted development and interactions of various factors. The work of Deleuze and Guattari (1987) has provided early childhood education in Japan with a valuable tool for supporting children's learning through negotiating between the segments of construction and those of reconstruction in order to deconstruct children's experiences towards positive becomings.

In sketching the learning experiences for Japanese children that considers their becomings, the findings seem to present a linier model of stability-fluidity-unpredictability. However, the aim of the study was to illustrate a way in which findings could be placed in the assemblage framework and in so doing to discuss the complex functions and roles of multiple segments in children's learning and becoming within the scope of family-preschool continuum. Considering parents' conceptions of families and preschools and their contributions to children's learning, we need to make another look at the assemblage process intersected by the segments and lines of the two territories and how they feed into the experiences and outcomes of children's overall being.

We now return to our question: what is the learning experience of Japanese children as perceived by their parents? Learning means children engaging in at least three types of experiences: 1) family and preschool structures and organizations; 2) practical activities and relationships with others 3) free play, everyday encounters, personal interest and following teachers. For the parents, children's learning is created by the territorial lines and the intersections of the stable, fluid and transforming elements. The unifying feature of the two territories, namely their homes and preschools, is therefore that they are each built around these experiences for children, so children become 1) appropriate members in the family and preschool; 2) respected individuals and autonomous and communicative social players; 3 ) playful, interested and real-life explorers under teachers' close support.

\section{Limitations}

There are two limitations to be acknowledged. First, the sample was not randomly selected and was not representative of the diversity of Japanese families. We engaged with only 130 Japanese parents from two preschools. Because of this, on an empirical level, the study only reported what we found from these participants. However, on a theoretical level, the study provided a provocative lens for understanding Japanese children's learning as multifaceted experiences and their contexts as the assemblage of movements of territorial lines that 
constructed, reconstructed and potentially transformed children's experiences.

In addition, this study relied on data from parents' questionnaires and snapshots of parent behaviours in the preschools. Although accessing these data may provide a limited view, we adopted several strategies to offset this limitation. First, one researcher was native Japanese and an educational professor as well as a mother herself. Her intimate knowledge of children, parents, and Japanese early childhood education informed our understanding of the parents' views and helped to place our analysis of the data into a more meaningful context. Both researchers engaged in a fully collaborative analysis of the data, serving to provide critical reflexivity in the process of data analysis. Second, we designed the questions as open-ended, so as to allow parents to answer them in detail. Third, the preschools were chosen because of the parents' educational backgrounds. Almost all the parents who answered the questions had a university degree so they were more likely to provide thoughtful responses. Fourth, our research is well grounded in the literature and the assemblage theory. The findings are consistent with and add a further dimension to previous studies and they are well informed by the associated ideas and concepts of the assemblage theory.

\section{Conclusion}

Children's learning is often premised on a sense of what children learn and how they learn and thus understood as a process and/or outcome. In this study, the concept of assemblage lent itself to comprehending Japanese children's learning through their parents' experiences and perspectives that centred on children's day-to-day lives in order to reveal various elements in their families and preschools so as to open territories and identify positive possibilities with the aim of sketching a full picture in children's learning and becoming.

Notions of the uchi and soto worlds in Japanese children's early childhood education have a central place in the concerns of this study. While it is not the aim of the study to question this tradition, we invoked Deleuze and Guattari's assemblage for its potential to deconstruct home/school dualisms in children's education and in this way privileged curiosity about what the parents saw children's learning in these two worlds, and in so doing providing a preliminary sketch of the assemblage which was directly relevant to the main thinking of the study, namely children's learning trajectories. In an assemblage space, home and preschool were perceived by the parents as both constructing children's stable constructs of membership, and reconstructing relationships and learning practices. Everyday experience, free play, children's own interests and teachers' teaching were considered as deconstructing the pathway of children's learning, thereby actualizing a breakaway in children's becomings.

The study contributes to the current literature in that it provides Japanese parents' perspectives of children's learning and through this, sketches the learning trajectories for Japanese children. The findings add to extant research by revealing a fuller range of segments in Japanese children's soto and uchi worlds which have opened up spaces beyond the dualistic practices, where new possibilities could emerge through constructing, reconstructing and deconstructing territorial segments within and between the two worlds. 


\section{References}

Aspinall, R. (2016). Children's rights in a risk society: The case of schooling in Japan. Japan Forum, 28(2), 135-154. https://doi.org/10.1080/09555803.2015.1076871

Bear, C. (2013). Assembling the sea: Materiality, movement and regulatory practices in the Cardigan Bay scallop fishery. Cultural Geographies 20, 21-41. https://doi.org/10.1177/1474474012463665

Burke, R. (2008). Becoming individuals together: Socialization in the Japanese preschool sites. A Journal of Social Anthropology and Cultural Studies, 5(2), 135-160.

Burke, R. (2014). Mind of child: The evolving role of mother in the Japanese early childhood context. Не Кири, 3(3), 54-63. https://doi.org/10.11157/sites-vol5iss2id105

Colebrook, C. (2002).Understanding Deleuze. Australia, NSW: Allen \& Unwin.

Currier, D. (2003). Feminist technological futures: Deleuze and body/technology assemblages, Feminist Theory, 3(3), 321-338. https://doi.org/10.1177/14647001030043005

Deleuze, G. (1995). Negotiations 1972-1990, Trans. M. Joughin. New York: Columbia University Press.

Deleuze, G., \& Guattari, F. (1987). A thousand plateaus. Trans. B. Massumi. London: Continuum. (Orig. pub. 1980.).

Duff, C. (2016). Assemblages, territories, contexts. International Journal of Drug Policy, 33, 15-20. https://doi.org/10.1016/j.drugpo.2015.10.003

Fox, N. (2014). The ill-health assemblage: Beyond the body-with-organs. Health Sociology Review, 20(4), 359-371. https://doi.org/10.5172/hesr.2011.20.4.359

Hara, H., \& Minagawa, M. (1996). From productive dependents to precious guests: Historical changes in Japanese children. In S. Harkness \& C. M. Super (eds.), Culture and human development: Japanese childrearing: Two generations of scholarship (pp. 9-30). New York: Guilford.

Hegde, A., Sugita, C., Crane-Mitchell, L., \& Averett, P. (2014). Japanese nursery and kindergarten teachers' beliefs and practices regarding developmentally appropriate practices. International Journal of Early Years Education, 22(3), 301-314. https://doi.org/10.1080/09669760.2014.948390

Hellman, A. (2016). Teaching reflective care in Japanese early childhood settings. Early Child Development and Care, 186(10), 1693-1702. https://doi.org/10.1080/03004430.2015.1124869

Hoffman, D. (2000). Pedagogies of self in American and Japanese early childhood education: A critical conceptual analysis. The Elementary School Journal. 101(2), 193-208. https://doi.org/10.1086/499664 
Izumi-Taylor, S. (2013). Scaffolding in group-oriented Japanese preschools. Young Children, March, 70-75.

Izumi-Taylor, S., \& Rogers, C. (2016). You are not the boss of me: How Japanese teachers delegate authority to children through play. Childhood Education. 92(3), 210-215. https://doi.org/10.1080/00094056.2016.1180894

Jones, I. (2017). What American schools can learn from Japanese moral education in schools? Tokyo Business Today, April 11 ${ }^{\text {th }}$. https://toyokeizai.net/articles/-/167166

Kamalipour, H., \& Peimani, N. (2015). Assemblage thinking and the city: Implications for urban studies. Current Urban Studies, 3, 402-408. https://doi.org/10.4236/cus.2015.34031

Lee, Y., Takenaka, K., \& Kanosue, K. (2015). An understanding of Japanese children's perceptions of fun, barriers, and facilitators of active free play. Journal of Child Health Care, 19(3), 334-344. https://doi.org/10.1177/1367493513519294

Nanakida, A. (2015). Early childhood education and care curriculum in Japan. In L, Huo, S, Neuman, \& A, Nanakida (Eds), Early childhood education in three cultures (pp. 25-38). Springer, Berlin, Heidelberg. https://doi.org/10.1007/978-3-662-44986-8_2

OECD (2011). 'Japan: A sustained story of excellence'. Lessons from PISA for the United States. OECD publishing. https://doi.org/10.1787/9789264096660-7-en

Potts, A. (2004). Deleuze on Viagra (or, what can a Viagra-body do?). Body \& Society, 10, 17-36. https://doi.org/10.1177/1357034X04041759

Semetsky, I. (2010). The folds of experience, or: Constructing the pedagogy of values. Educational Philosophy and Theory, 42(4), 476-488. https://doi.org/10.1111/j.1469-5812.2008.00486.x

Tobin, J., Hsueh, Y., \& Karasawa, M. (2009). Preschool in three cultures revisited: China, Japan, and the United States. Chicago: The University of Chicago Press. https://doi.org/10.7208/chicago/9780226805054.001.0001

Windsor, J. (2015). Desire lines: Deleuze and Guattari on molar lines, molecular lines, and lines of flight. New Zealand Sociology, 30(1), 156-171.

Yamamoto, Y. (2016). Gender and social class differences in Japanese mothers' beliefs about children's education and socialisation. Gender and Education, 28(1), 72-88. https://doi.org/10.1080/09540253.2015.1091917

Yamamoto, Y., \& Holloway, S. (2010). Parental expectations and children's academic performance in sociocultural context. Educational Psychology Review, 22(3), 189-214. https://doi.org/10.1007/s10648-010-9121-z

Yamamoto, Y., Holloway, S., \& Suzuki, S. (2016). Parental engagement in children's education: Motivating factors in Japan and the U.S. School Community Journal, 26(1), 45-65. 


\section{Macrothink}

International Journal of Education

ISSN 1948-5476

\section{Copyright Disclaimer}

Copyright for this article is retained by the author(s), with first publication rights granted to the journal.

This is an open-access article distributed under the terms and conditions of the Creative Commons Attribution license (http://creativecommons.org/licenses/by/3.0/). 